\title{
Tramas femeninas y violencia de género en la frontera bonaerense. Mujeres y blandengues desertores a finales del siglo XVIII
}

Resumen: Entre los estudios sobre la frontera y la historia de las mujeres en la sociedad colonial rioplatense, este trabajo analiza un corpus de juicios abiertos a desertores de la compañía de Blandengues de Buenos Aires a finales del siglo XVIII y recupera indicios sobre el rol de las mujeres y la vida en los fuertes. Para dar luz sobre el tejido social femenino en el contexto de la frontera, se rastrean distintas formas de violencia masculina ejercida contra las mujeres y se destaca la agencia femenina, a través de las tramas familiares, los vínculos comunitarios y afectivos.

Palabras clave: mujeres, frontera, violencia, blandengues desertores, género, sociabilidad femenina.

\section{Female networks and gender violence in the Buenos Aires borderlands. Women and blandengue deserters at the end of the 18th century}

Abstract: In between the studies of the Rio de la Plata borderlands and the history of women in colonial society, this paper analyzes a legal corpus of trials of deserters from the Blandengues company of Buenos Aires at the end of the Eighteenth century to trace the presence of women on this border region. We track down different forms of male violence against women through this military documentation, from domestic abuse, kidnaping, and rape, and identify female agency through their family networks and emotional ties.

Keywords: women, borderlands, violence, blandengue deserters, gender, female sociability.

\section{Tramas femininas e violência de gênero na fronteira de Buenos Aires. Mulheres e blandengues desertores no século XVIII}

Resumo: Entre os estudos sobre a fronteira e a história das mulheres na sociedade colonial rioplatense, este trabalho parte da análise de um corpus de ações judiciais abertas contra desertores da companhia militar de Blandengues de Buenos Aires, no final do século XVIII, e recupera indícios sobre o papel das mulheres e a vida nos fortes. Para lançar luz sobre o tecido social feminino no contexto da fronteira, rastreiam-se diferentes formas de violência masculina contra as mulheres, desde violência doméstica, roubo e estupro, mas também a agência feminina, por meio de seus laços comunitários, familiares e afetivos.

Palavras-chave: mulheres, fronteira, violência, blandengues desertores, gênero, sociabilidade feminina.

Cómo citar este artículo: Diana Roselly Pérez Gerardo, "Tramas femeninas y violencia de género en la frontera bonaerense. Mujeres y blandengues desertores a finales del siglo XVIII", Trashumante. Revista Americana de Historia Socia/ 18 [2021]: 124-145.

DOI: 10.17533/udea.trahs.n18a06

Fecha de recepción: 30 de octubre de 2020

Fecha de aprobación: 22 de abril de 2021

Diana Roselly Pérez Gerardo: Doctora en Historia de la Universidad Nacional Autónoma de México

[UNAM]. Investigadora del Instituto de Investigaciones Históricas de la misma universidad. ORCID: 0000-0001-6777-3081.

. Correo electrónico: dianaroselly@unam.mx 


\title{
Tramas femeninas y violencia de género en la frontera bonaerense. Mujeres y blandengues desertores a finales del siglo XVIII
}

\author{
Diana Roselly Pérez Gerardo
}

\section{Introducción}

as dinámicas de la frontera bonaerense a finales del siglo XVIII han sido Lanalizadas desde diferentes ángulos. En lo que concierne a la militarización de la línea de fuertes formada al sur y oeste del río Salado, destacan los diversos estudios sobre las relaciones interétnicas, las tensiones entre las autoridades locales y la política monárquica, los circuitos de circulación de personas y bienes, así como los conflictos y las negociaciones o la mediación entre los distintos grupos que confluyeron en este complejo fronterizo. Estos abordajes han dado lugar a una historiografia crítica que ha repensado las relaciones fronterizas, los procesos de subjetivación, mestizaje, etnificación y etnogénesis, así como el concepto mismo de frontera. ${ }^{1}$

Por otro lado, la historiografia que ha abordado el papel de las mujeres dentro de la sociedad colonial rioplatense ha descrito con acuciosidad el ámbito doméstico y familiar, el ámbito religioso, la relación entre las mujeres de distintos estratos y el trabajo, su vinculación con la caridad, la violencia intrafamiliar y la agencia femenina en espacios en los que las mujeres ejercieron papeles tradicionalmente vinculados a los varones como el de jefas de familia y propietarias. ${ }^{2}$ Otros ejes de

1. Florencia Roulet, "Fronteras de papel. El periplo semántico de una palabra en la documentación relativa a la frontera sur rioplatense de los siglos XVIII y XIX", Revista Tefros 4.2 (2006):1-26.

2. Sandra Olivero, "Hogares femeninos en el Buenos Aires colonial", Nuevo Mundo Mundos Nuevos, Colloques (2008), doi: 10.4000/nuevomundo.43783; Alicia Fraschina, Mujeres consagradas en el Buenos Aires colonial (Buenos Aires: Eudeba, 2010); Silvia Mallo, "La mujer rioplatense a fines del siglo XVIII. Ideales y realidad”, Anuario del IEHS 5 (1990): 117-132; Carlos A. Mayo, Estancia Y sociedad en La Pampa (1740-1820) (Buenos Aires: Biblos, 1995) 165-190; María Selina Gutiérrez Aguilera, "Mujeres trabajadoras: la subsistencia en el Buenos Aires del siglo XVIII", El Futuro del Pasado 3 (2012): 67-90; María Selina Gutiérrez Aguilera, "Mujeres agregadas en el Buenos Aires del siglo XVIII: caridad y solidaridad", Nuevo Mundo Mundos Nuevos, Débats (2012), doi:10.4000/ nuevomundo.64111; Alejandra Lamas y Guillermo O. Quinteros, "Violencia intrafamiliar y acción judicial en Buenos Aires, 1785-1821", Familias de ayer y de hoy: las sociedades ibéricas 
análisis se han ocupado de las mujeres indígenas y mujeres esclavas en la sociedad colonial, de la proporción demográfica que representaba la población femenina en la urbe y de instituciones para mujeres, como los conventos y las casas de recogida. ${ }^{3}$ Por otra parte, existen trabajos que abordan las normativas, las prácticas y las transgresiones asociadas a la sexualidad de las mujeres en la sociedad colonial. ${ }^{4}$ Así, prácticas como el amancebamiento, las amistades ilícitas, ${ }^{5}$ el adulterio o el estupro y la violación aparecen en los estudios sobre las mujeres como rasgos inherentes a la constitución misma de lo femenino en esta sociedad. Finalmente, en lo que concierne a las mujeres en la frontera, el cautiverio se ha convertido en uno de los temas más populares alrededor del cual se han cifrado varios ejes problemáticos, como la diferencia entre el cautiverio masculino y el femenino y, dentro de este, los contrastes entre el cautiverio de mujeres blancas y el de mujeres indígenas; su relevancia como informantes después de su redención, y las agencias de algunas de ellas como mediadoras y negociadoras de la paz. ${ }^{6}$

Este trabajo se ubica en el intersticio de estas aproximaciones. Al trabajar con una serie de juicios sumarios abiertos a militares de la compañía de Blandengues acusados de deserción fue posible asociar esta falta a otros tantos crímenes como el asesinato, las trifulcas y las heridas, el "pasarse con los indios" y el robo. Si bien la evasión de los deberes militares estaba tipificada como falta grave dentro de las ordenanzas y normativas que regían a los distintos los cuerpos castrenses, las penas

y el Río de la Plata, comps. Guillermo O. Quinteros y M. Pablo Cowen (La Plata: Universidad Nacional de La Plata, 2018) 173-204; José Luis Moreno, "Conflicto y violencia familiar en el Río de la Plata 1770-1810", Revista de Historia Social y de las Mentalidades 6 (2002): 13-38; Claudia Contente, "Las mujeres, sus bienes y estado civil, entre costumbres y legislación. Las jefas de familia de la campaña de Buenos Aires de los siglos XVIII y XIX”, Revista de Historiografía 26 (2017): 67-83, doi: 10.20318/revhisto.2017.3699.

3. María Selina Gutiérrez Aguilera, "Mujeres esclavas bajo la autoridad femenina: entre dóciles y rebeldes. (Buenos Aires, siglo XVIII)", Historia y Memoria 12 (2016): 121-155; Susan M. Socolow, "Buenos Aires: Puerto Atlántico e Hinterland en el siglo XVIII", Revista de Estudios Marítimos y Sociales 2.2 (2009): 9-20; Natalia Soledad Salerno, "Mujeres indígenas recluidas en la Casa de Recogimiento (Buenos Aires, etapa colonial tardía)" (Tesis de licenciatura en Historia, Universidad Nacional del Sur, 2014).

4. Ramón Pedro Yanzi Ferreira, "Los delitos de orden sexual: violencia, incesto y estupro en la jurisdicción de Córdoba del Tucumán (siglo XVIII)", Cuaderno de Historia 15 (2005): 28-45; Jaqueline Vassallo, "Delincuentes y pecadoras en la Córdoba tardo colonial", Anuario de Estudios Americanos 63.2 (2006): 97-116.

5. Carlos A. Mayo, "Amistades ilícitas: las relaciones extramatrimoniales en la campaña bonaerense, 1750-1810", Cuadernos de Historia Regional 2 (1985): 3-9; Antonio Fuentes-Barragán, "Quebrantos de la moral conyugal: amistades ilícitas en el Buenos Aires tardocolonial", Naveg@mérica 15 (2015): 1-23.

6. Florencia Roulet, "Mujeres, rehenes y secretarios: mediadores indígenas en la frontera sur del Río de la Plata durante el período hispánico", Colonial Latin American Review 18.3 (2009): 303 337, doi: 10.1080/10609160903336101; Marcela Tamagnini y Graciana Pérez Zavala, "Mujeres de frontera: entre el cautiverio y el estigma" (IV Congreso Chileno de Antropología, Colegio de Antropólogos de Chile, 2001) 690-696. 
dictadas en los juicios raras veces se cumplían. ${ }^{7} \mathrm{Su}$ denuncia, juicio y sentencia dependieron siempre de la imperante necesidad de mantener a los efectivos necesarios para la defensa de la frontera. No obstante, la deserción, independientemente de sus motivos, estuvo vinculada a distintos agravantes, entre los cuales destaca el pillaje, que oscilaba entre el hurto de piezas de ropa, herramientas o armas y ganado, y el asalto premeditado de pulperías y el robo de mujeres. ${ }^{8}$

Es entonces que el análisis de la deserción de las filas de los cuerpos militares, además de abrir rutas de análisis sobre las estructuras militares de la frontera, se convierte en un prisma a través del cual se pueden perfilar formas de sociabilidad y dinámicas cotidianas de la vida en la frontera. Con base en lo anterior, es interés de este trabajo destacar la vida de las mujeres en los fuertes, sus ámbitos de acción y las tramas de parentesco y solidaridad tejidas entre ellas, así como los conflictos y los márgenes de flexibilidad que el modelo aprobado de lo femenino adquiría en los contextos de frontera.

\section{Las fronteras de Buenos Aires}

Desde su fundación, Buenos Aires tuvo el desafio de atender diversas fronteras y de idear estrategias defensivas que fueran efectivas y compatibles con los múltiples intereses que confluían en ellas. Para el siglo XVIII, los límites imperiales entre España y Portugal, al compás de la política internacional, marcaban los pasos de las milicias para la defensa de territorios específicos como la Banda Oriental. Por el lado de la Pampa, primaba la urgencia por contener las incursiones de indios, proteger los asentamientos y estancias en los cordones defensivos, así como, idealmente, avanzar la colonización hacia nuevos territorios más allá del río Salado. En su calidad de puerto, Buenos Aires estaba inmersa en dinámicas comerciales y de guerra, especialmente cuando la amenaza inglesa se vertía sobre las aguas rioplatenses. Por si fuera poco, tuvo la obligación de cooperar en la defensa de la frontera de Santa Fe y, una vez conformado el virreinato del Río de la Plata, fue responsable de la defensa de las rutas mercantiles desde el Potosí y se vinculó a la frontera araucana. En la articulación de estos múltiples agentes e intereses, el esfuerzo militar fue constitutivo de la conformación histórica de la sociedad bonaerense y de las múltiples fronteras que atendía.

El espacio analizado es producto de la política que a inicios de la década de 1770 intentó un sistema de defensa de fuertes y fortines, ${ }^{9}$ en donde, además de

7. En las ordenanzas de 1768 se determina la pena de muerte como castigo a la deserción. Fernando de Salas López, Ordenanzas militares en España e Hispanoamérica (Madrid: Editorial Mapfre, 1992) 100.

8. Diana Roselly Pérez Gerardo, "Blandengues desertores: dinámicas sociales de frontera en Buenos Aires a finales del siglo XVIII", Fronteras de la Historia 25.2 (2020): 94-118, doi: $10.22380 / 20274688.1141$

9. Aunque para el siglo XVIII los fuertes, fortines y guardias eran pequeñas fortificaciones, sus diferencias estribaban en aspectos constructivos y en la dotación militar. Algunas, como Luján, eran permanentes, y otras, pasajeras. Mariana Canedo, "Fortines y pueblos en Buenos Aires del 
las milicias de vecinos, los diversos cuerpos militares de veteranos cobraban importancia y aumentaban su número de efectivos. ${ }^{10} \mathrm{~A}$ finales de esta década, el plan integral para afianzar la frontera, implementado por el virrey Joseph de Vértiz (1778-1784), incluía la reforma del Cuerpo de Blandengues, ${ }^{11}$ el impulso a la inmigración española y políticas de poblamiento para reclutar de forma obligatoria a familias sin arraigo comprobable en la campaña y trasladarlas a los fuertes fronterizos. ${ }^{12}$ La política defensiva dependía entonces de los poblados protegidos por un asentamiento militar. ${ }^{13}$ Bajo estos parámetros, la línea avanzaba casi paralela al río Salado e integraba a los fuertes de Chascomús, Ranchos, Monte, Luján, Salto, Rojas y a los fortines de Lobos, Mercedes, Navarro, Areco y Melincué. Los casos aquí analizados corresponden a varios de estos puestos.

De este modo, durante la década de 1780, la frontera vivió un incremento de las alcaldías de hermandad, fuertes fronterizos y poblados rurales, ${ }^{14}$ varios de los cuales se convirtieron en núcleos mercantiles y articularon diversas relaciones interétnicas. El crecimiento de la población rural se había sustentado en la migración de personas que buscaban mejores oportunidades de acceso a la tierra y que paulatinamente conformaron unidades productivas pequeñas y medianas. ${ }^{15} \mathrm{La}$ línea de frontera, a finales del siglo, estaba planeada para que sus colonos hicieran producir la tierra en tiempos de paz y defendieran la región cuando los diversos desequilibrios en las relaciones con los indígenas abrían las hostilidades.

siglo XVIII. ¿Una política de urbanización para la frontera?”, Mundo Agrario 7.13 (2006).

10. Sara Ortelli, "La frontera y el mundo indígena pampeano", Historia de la provincia de Buenos Aires, t. 2, dir. Raúl O. Fradkin (Buenos Aires: Edhasa, 2012) 168.

11. La creación del Cuerpo de Blandengues se enmarca en la política militar impulsada por los borbones después de la Guerra de los Siete Años. En 1752, a instancia del Cabildo de Buenos Aires, se fundaron tres compañías a sueldo para el resguardo de la frontera indígena que recibieron el nombre de Blandengues. Financiadas por el ramo de guerra a través de cuatro impuestos especiales, estas compañías sufrieron varios cambios desde su creación. Carlos A. Mayo y Amalia Latrubesse, Terratenientes, soldados y cautivos: la frontera, 1736-1815 (Mar del Plata: Universidad Nacional de Mar del Plata / Colegio Nacional Dr. Arturo U. Illia / Grupo Sociedad y Estado, 1993); María Eugenia Alemano, "Los Blandengues de la Frontera de Buenos Aires y los dilemas de la defensa del Imperio (1752-1806)", Fronteras de la Historia 22.2 (2017): 44-74, doi: 10.22380/20274688.104.

12. José Mateo, Población, parentesco y red social en la frontera. Lobos (provincia de Buenos Aires) en el siglo XIX (Mar del Plata: Grupo de Investigación en Historia Rural Rioplatense, Universidad Nacional de Mar del Plata, 2001).

13. En 1780 se dictó un bando para presionar a los pobladores a mudarse cerca de los fuertes. Guillermo Banzato y Sol Lanteri, "Forjando la frontera. Políticas públicas y estrategias privadas en el Río de la Plata, 1780-1860”, Historia Agraria 43 (2007): 439.

14. La red de pueblos rurales que se estaba conformando a finales del periodo colonial no alcanzó el estatuto jurídico de villas, que solo obtuvo Luján en 1756. María E. Barral y Raúl O. Fradkin, "Los pueblos y la construcción de las estructuras de poder institucional en la campaña bonaerense (17851836)", Boletín del Instituto de Historia Argentina y Americana "Dr. Emilio Ravignani" 27 (2005): 7-48.

15. Raúl O. Fradkin, "Las milicias de caballería de Buenos Aires, 1752-1805”, Fronteras de la Historia 19.1 (2014): 128; José Luis Moreno y José Antonio Mateo, "El 'redescubrimiento' de la demografia histórica en la historia económica y social”, Anuario IEHS 12 (1997): 35-55. 
La frontera como "espacio políticamente concertado"16 implicó esfuerzos por articular a los diversos cuerpos militares ${ }^{17}$ y la creación de universos de gobernabilidad para las sociedades que ahí se confrontaban y convivían. Esto trajo como consecuencia la maleabilidad de los marcos normativos que operaban en espacios plenamente integrados al orden colonial. En la documentación del siglo XVIII, la frontera se entendía como un espacio de transición entre el ámbito de control, más o menos efectivo, del estado colonial y los territorios libres indígenas. ${ }^{18}$ Por su carácter de umbral, y por la intensa movilidad y confluencia de personas de orígenes diversos, la franja fronteriza fue propicia para procesos de mestizaje y amparó a un amplio repertorio de sujetos liminales, que, por sus complejas tramas interpersonales, desafiaban al límite.

Ante la presencia de diversos tipos de proscritos, renegados, aindiados, tránsfugas, desertores y demás individuos marcados por la ambigüedad y la indeterminación, las autoridades hispanocriollas intentaron concentrar y disciplinar a estas poblaciones. Desde 1760, cuando Carlos III autorizó la existencia del Cuerpo de Blandengues, añadió la recomendación de reunir a una junta de notables "para establecer normas de control sobre los soldados y sus mujeres". ${ }^{19}$ De acuerdo con Florencia Roulet, las "políticas hacia la frontera", tanto en el siglo XVIII como en el XIX, "respondieron al doble objetivo de contener al indígena (el "otro" externo, percibido como enemigo) y el de someter al imperio de la ley a los díscolos habitantes rurales amantes de la libertad y el ocio (el "otro" interno, percibido como criminal)". ${ }^{20}$

\section{Mujeres, frontera y el ideal de lo femenino}

Uno de los rasgos que es necesario retomar sobre la construcción de las fronteras es su concepción como espacios marcados por la violencia, "la arbitrariedad, el riesgo, la ilegalidad, la impunidad y el desamparo más absolutos". ${ }^{21}$ Así, la imagen de la frontera se arraigó como un universo predominantemente masculino o como "el ámbito de los caudillos, de los hombres fuertes que dominan a su séquito de hombres". ${ }^{22}$ Esta noción ha invisibilizado el rol de las mujeres (indígenas,

16. En cuanto espacio políticamente concertado, la frontera contiene universos de gobernabilidad para las sociedades concurrentes que se construyen y se redefinen en el conflicto y en la convivencia armónica con el "otro". Eugenia Alicia Néspolo, "La 'Frontera' Bonaerense en el siglo XVIII un espacio políticamente concertado: fuertes, vecinos, milicias y autoridades civilesmilitares", Mundo Agrario 7.13 (2006): 2.

17. Florencia Carlón, "Sobre la articulación defensiva en la frontera sur bonaerense a mediados del siglo XVIII: un análisis a partir de la conflictividad interétnica”, Anuario del Centro de Estudios Históricos "Prof. Carlos S. A. Segreti" 8.8 (2008): 277-298.

18. Roulet, "Fronteras de papel" 14.

19. Mayo y Latrubesse 20.

20. Roulet, "Fronteras de papel" 6-7.

21. Roulet, "Fronteras de papel” 15.

22. Silvia Ratto, "El debate sobre la frontera a partir de Turner. La New Western History, los Borderlands 
mestizas o hispanocriollas), más allá de su condición de botín de guerra, tanto en el cautiverio como en otras operaciones de violencia que buscaban desarticular al enemigo. ${ }^{23}$ Paralelamente, la proyección de los espacios fronterizos como refugio de prácticas y sujetos al margen de la normatividad abrió el horizonte para flexibilizar los modelos deseables de lo femenino. Silvia Mallo señala que incluso la sociedad porteña de Buenos Aires, influenciada por su cercanía con la frontera, a pesar de ser una sociedad patriarcal, estaba dispuesta a "modificar las formas tradicionales de vida y evitar los patrones estrictos y rígidos de comportamiento dentro de los límites de una sociedad cristiana católica". ${ }^{24}$

En los procesos del juzgado del crimen de Buenos Aires se encuentran mujeres acusadas de diversos delitos y pecados ${ }^{25}$ relacionados con faltas que contravenían a la familia y al matrimonio, como el adulterio, el amancebamiento y el incesto; las que se vinculaban a las infracciones de los modelos de decencia, como las injurias o los escándalos públicos; las que involucraban a mujeres en robos y pillajes, algunas veces como cómplices; así como aquellas en las que las mujeres ejercen la violencia, como lesiones de distinto grado hasta el homicidio. ${ }^{26}$ Por otro lado, las mujeres denunciaron diversas formas de violencia: malos tratos reiterados, bigamia de sus cónyuges o promesas de matrimonio incumplidas por parte de los pretendientes. Selina Gutiérrez ha podido clasificar los casos de injusticias, abusos, ignominia, agravios y

y el estudio de la frontera en Latinoamérica", Boletín del Instituto de Historia Argentina y Americana "Dr. Emilio Ravignani” 24 (2001): 119.

23. El cautiverio, en general, se vincula "al objetivo de infligir daño, más allá de lo material, a la capacidad moral y psicológica de resistencia de los enemigos, pues cada acto de arrebato cuestionaba la capacidad de protección de los más desprotegidos de una comunidad". Yéssica González, "Indias blancas tierra adentro. El cautiverio femenino en la Frontera de la Araucanía, siglos XVIII y XIX", Anuario Colombiano de Historia Social y de la Cultura 43.2 (2016):189, doi: 10.15446/achsc.v43n2.59076.

24. Mallo, "La mujer rioplatense" 117.

25. "Pecados son entonces aquellos actos que dicen los textos y tradiciones de carácter religioso; delitos, los que a su vez figuran en los jurídicos". Esta definición tiene implicaciones que contemplan las nociones de bien y mal, los niveles de conciencia involucrados al cometer la trasgresión, entre otros. Véase Bartolomé Clavero, "Delito y pecado. Noción y escala de transgresiones", Sexo barroco y otras transgresiones premodernas, comps. Francisco Tomás y Valiente y otros (Madrid: Alianza Editorial, 1990) 59.

26. José Luis Moreno analiza, para Buenos Aires y su campaña, 218 causas en las que hay violencia contra mujeres. El mayor número lo ocupan los homicidios, seguidos por violación y estupro, heridas y malos tratos, reclusión, bigamia y amancebamiento. Moreno, "Conflicto y violencia" 15-16. Para el caso de Córdoba, Jaqueline Vassallo encuentra 106 mujeres que fueron procesadas por la justicia ordinaria, de las cuales, alrededor de la mitad fueron acusadas por amancebamiento; siguen en número de casos, el robo y el homicidio, y posteriormente una decena de acusadas por injurias, ocho por adulterio, cinco por lesiones, otras cinco por incesto, dos por escándalo, una por bigamia y otra por falsificación de moneda.Vassallo, "Delincuentes y pecadoras" 103. Los trabajos sobre mujeres en esta región se han concentrado en espacios urbanos no fronterizos. Jaqueline Vassallo, “¿Historia de las mujeres o historia de género? Una aproximación al estudio de las mujeres en la ciudad de Córdoba a fines del siglo XVIII", Revista Dos Puntas 6.11 (2015): 153-178. 
violencia en los que las mujeres aparecen como víctimas, aunque también considera a aquellas que decidieron hacer justicia con sus propias manos. ${ }^{27}$

Para finales del siglo XVIII, las reformas borbónicas habían apuntado hacia la modernización de la economía, la sociedad y las instituciones, pero también intentaban racionalizar las prácticas cotidianas, costumbres y comportamientos para imponer un efectivo control de la población, para lo cual se fortaleció el papel atribuido a la familia y a valores, como el honor, a fin de reforzar la estructura patriarcal de la sociedad colonial. ${ }^{28}$ Sin embargo, las especificidades de las zonas fronterizas implicaron un margen de acción femenina que, si bien no escapaba a los cánones, normas y sanciones, presentaba algunas particularidades.

Comencemos por advertir que este primer acercamiento a las sociabilidades femeninas de la cadena de fuertes de la frontera pampeana proviene del análisis de juicios abiertos a blandengues desertores entre 1786 y 1801, que se encuentran en el Archivo General de la Nación Argentina (AGNA). A partir de este corpus, cuyo objetivo primordial era investigar y sancionar las transgresiones cometidas por los efectivos militares, se rastrearon los testimonios (siempre fragmentarios y mediados) de mujeres involucradas en las deserciones. ${ }^{29}$ Con todo y los sesgos inherentes a este tipo de documentación y de entre los resquicios de la documentación militar, que por antonomasia se ha concebido como una esfera predominantemente masculina, recuperamos los indicios sobre el rol de las mujeres para dar luz sobre el tejido social femenino en el contexto de la frontera.

\section{Liviandades de frontera}

Carlos Mayo y Amalia Latrubesse afirman, en el análisis del perfil social de los blandengues, que las "humildes mujeres de la frontera llevaban una vida sexual más libre que sus congéneres de las capas altas y no carecían de determinación en

27. María Selina Gutiérrez Aguilera, "Conductas violentas, realidades cotidianas. Familia, sociedad y convivencia en el Buenos Aires del siglo XVIII", Procesos Históricos. Revista de Historia y Ciencias Sociales 28 (2015): 76-91.

28. El honor como medio simbólico de control social fue reforzado por la Real Pragmática de 1776 (1778 en América), que aumentó el poder patriarcal como forma de reorientación de las relaciones familiares. Eugenia Bridikhina, Sin temor a Dios ni a la justicia real. Control social en Charcas a fines del siglo XVIII (La Paz: Instituto de Estudios Bolivianos / Universidad Mayor de San Andrés, 2000) 134. El honor alude tanto a los ideales morales y a la conducta virtuosa como a la situación social de los individuos al designar dignidades derechos y precedencias dentro de la jerarquía social. María Alejandra Fernández, "Familias en conflicto: entre el honor y la deshonra", Boletín del Instituto de Historia Argentina y Americana "Dr. Emilio Ravignani” 20 (1999): 9.

29. Es necesario recordar que los expedientes judiciales "constituyen la expresión de un conflicto" en el que "cada actor decodifica la realidad, manipula la norma a su favor y busca las distintas maneras de resolver las diferencias".Viviana Kluger, "El expediente judicial como fuente para la investigación histórico-jurídica. Su utilidad para el estudio de la historia de la familia colonial iberoamericana”, Passagens. Revista Internacional de História Política e Cultura Jurídica 1.1 (2009): 5, doi: 10.5533/1984-2503-20091104. 
la elección de su a veces cambiante pareja". ${ }^{30}$ Los autores destacan, por ejemplo, los casos de adulterio en flagrancia, amistades ilícitas, mujeres que huyen con sus amantes o que son golpeadas por sus maridos ante sospechas de celos, y resaltan el caso de Tomasa Cabrera, a quien Julián Baldés, después de molerla a golpes tras sorprenderla con otro hombre, le preguntó con cuál de los dos se quería quedar, con lo que le dejaba a ella la posibilidad de elección. Pero, a pesar de la intención de los autores de esbozar un margen más amplio de acción y negociación femenina en la frontera, en esa interpretación subyace una noción de lo femenino que restringe su acción al de su sexualidad. ${ }^{31}$

Al revisar la trama en la que se encontraba inmersa Tomasa Cabrera en la frontera de Chascomús en 1793, sobresalen varios elementos que trascienden sus prácticas sexoafectivas. Julián Baldés, soldado de la primera compañía del cuerpo de Blandengues de ese fuerte, fue acusado ante las autoridades militares por haberle cortado la trenza a Tomasa, acción que implicaba un desprestigio inmediato de la mujer y que se justificaba en la declaración del acusado por haber sido encontrada con "con un paysano llamado Cabral". Sin embargo, Baldés no era el marido de Tomasa. ${ }^{32}$ Ella estaba casada con otro blandengue de nombre José Antonio Leyva. Pero si acaso llama la atención la doble relación de adulterio que sostenía Tomasa, resulta aún más interesante para el análisis de las sociabilidades y la preservación del orden en los puestos fronterizos, el que todos los implicados accedieran a la petición de Tomasa de evitar que su marido se enterara. El propio teniente coronel Francisco Balcarce pidió en el parte que envió a la guardia que se procediera en las investigaciones "con la posible reserva y a fin de que el marido de la citada mujer que parece no se enquentra noticioso de lo acaecido con ella, no lo trascienda". Pide además que "con algún pretexto, como el de comisionarlo a alguna diligencia lo separara de aquel puerto para poder formar la sumaria en su ausencia". ${ }^{33}$

Julián Baldés era natural de Montevideo, "moreno", de 23 años, y había desertado de esa plaza el año anterior. De "genio fuerte e ynsultante", había sido arrestado diez meses antes por el cabo Manuel San Román después de haberlo encontrado peleando con un miliciano en cuya refriega habían salido heridos ambos. ${ }^{34}$ De Tomasa no sabemos su edad ni procedencia, pero declaró "que su oficio

30. Mayo y Latrubesse 79.

31. Según Eugenia Soledad Ambroggio, para el caso de Córdoba, en la campaña "la promiscuidad de las relaciones era bastante frecuente". Eugenia Soledad Ambroggio, "Género y violencia en la Córdoba tardo colonial. La lealtad y el honor en las relaciones formales e informales” (XI Jornadas Interescuelas Departamentos de Historia, Universidad de Tucumán, 2007) 14.

32. Cortar el pelo a una mujer implicaba humillación y deshonor en la medida en que se trataba de una marca de desagravio. Las motivaciones sentimentales solían asociarse con el ejercicio de la venganza por parte del varón. Ambroggio 5.

33. Francisco Balcarce, "Carta a Pedro Espinosa”, Frontera de Chascomús, 17 de octubre de 1793. Archivo General de la Nación, Argentina (AGNA), Buenos Aires, Sala IX, División Colonia, Sumarios Militares, leg. 12-7-8, exp. 10, f. 1v-2.

34. "Declaración del testigo Miguel Román”, Frontera de Chascomús, 25 de octubre de 1793. AGNA, Buenos Aires, Sala IX, División Colonia, Sumarios Militares, leg. 12-7-8, exp. 10, f. 10v. 
que ejerce es de ylar y coser, y demás trabajos pertenecientes ha una mujer que bibe en esta guardia de Chascumus". ${ }^{35}$

Las versiones de ambos difieren en los motivos que tuvo Baldés para cortarle el pelo. Los dos declararon haber tenido "amistad", pero ella aseguraba que ya no deseaba tenerla más por los disgustos que estaba pasando con su marido. Cuando se lo comunicó a Baldés, este le tusó la trenza y le advirtió que "aquello lo hacia para que no engañase ha otro" ${ }^{36}$ Ella mandó a pedirle la trenza para evitar que su marido la viera sin pelo, pero, al no concederle su solicitud, lo acusó con el capellán don Judas Tadeo de la Poveda, a quien le entregó la trenza, que, a su vez, llevó con don Manuel Fernández, capitán de ese fuerte y que le fue devuelta a Tomasa por un sargento de la compañía de nombre Juan Barreda.

En la versión de Baldés, un día encontró a Tomasa con un hombre de apellido Cabral, que le estaba "pegando de moquetes". Después de intervenir y advertir a ese hombre que Tomasa era su "amiga" ambos se retiraron, pero Baldés volvió al otro día y también la golpeó. Después de castigarla con un rebenque, "le pregunto que con qual de los dos se quería quedar, o seguir amistad”, ella contestó que con él "mientras su marido no lo supiese o los llegara a pillar". Pero cuando le cortó el pelo fue porque una noche la volvió a encontrar con el referido Cabral "donde ya le faltó el sufrimiento de ver el modo en que se portaba la referida Thomasa". ${ }^{37}$ La sentencia fue de tres años de presidio para el agresor, pero se advertía que se debía aminorar la pena "por no concurrir en la mujer expresada la circunstancia de onrrada”. El defensor de Baldés argumentó "la relajada conducta, escandalosa vida y inquino proceder de Tomasa Cabrera" por sostener con dos hombres "trato tan perjudicial" y la responsabilizaba de "las funestas consecuencias".

Varios aspectos se destacan de este embrollo, que trasciende a la mera infracción del modelo matrimonial católico y al adulterio en su concepción de ofensa a terceros. ${ }^{38}$ Por un lado, la precariedad material general que solía privar en los puestos de frontera se refleja en que la "amistad" entre Julián y Tomasa iba acompañada del suministro de "quanto podía, para los menesteres de dicha mujer", beneficio que Baldés siguió proporcionando incluso después de haberla encontrado la primera vez con Cabral. A propósito del sostén económico, se sabe que esta mujer desempeñaba un oficio como hilandera y costurera, pero surge la pregunta por el marido, sus ausencias y su capacidad de aprovisionamiento a partir del sueldo

35. "Declaración de Thomasa Cabrera", Frontera de Chascomús, 25 de octubre de 1793. AGNA, Buenos Aires, Sala IX, División Colonia, Sumarios Militares, leg. 12-7-8, exp. 10, f. 9v.

36. "Declaración de Thomasa Cabrera", f. 8.

37. "Declaración del Acusado Julián Baldés", Frontera de Chascomús, 28 de octubre de 1793. AGNA, Buenos Aires, Sala IX, División Colonia, Sumarios Militares, leg. 12-7-8, exp. 10, f. 13v.

38. Sobre el adulterio, en la tradición judeocristiana desde el Antiguo testamento hasta el Concilio de Trento y de la legislación en torno a él en la época colonial, véase Teresa Lozano Armendares, No codiciarás la mujer ajena. El adulterio en las comunidades domésticas novohispanas. Ciudad de México, siglo XVIII (México: Universidad Nacional Autónoma de México, 2005) 27-65, 143-192. 
que tenía como blandengue. ${ }^{39}$ Resulta singular que no se mencione la existencia de hijos, aunque subyace el interés de todos en que el matrimonio consagrado se perpetuara a pesar del adulterio.

Lo que más sobresale en este caso es la disposición de todos los involucrados (el coronel Balcarce, el capitán del fuerte, el capellán, el defensor, los tres testigos y el acusado) para guardar el secreto. Esto contrasta directamente con uno de los elementos que solían acompañar las denuncias de adulterio: el escándalo, que es "ocasión de daño y ruina espiritual en el prójimo". ${ }^{40}$ Dos especificidades saltan a la vista. La primera es que no se trata de una causa criminal por adulterio ni por tratos ilícitos, sino por el atentado cometido por un efectivo de la compañía de Blandengues en contra de una mujer. ${ }^{41}$ Por ello, los testigos son militares, aunque esto no exime que las relaciones ilícitas de Tomasa fueran conocidas por los vecinos. La segunda es que la súplica de discreción de la mujer bajo el argumento de prevenir "la mala vida que de ello le puede resultar", o incluso la posibilidad de ser asesinada por su marido, parece insuficiente para justificar el consenso colectivo de dejar al cornudo en la inopia. Al conceder en ello no se atendía la vergüenza y humillación del marido, tampoco se perseguía ni se castigaba a la mujer por adúltera ni por injuria u ofensa a la moral pública. La potencial violencia que desataría informar al marido no parece reducirse a Tomasa, pues los dos varones implicados habían cometido agravios físicos hacia ella. De modo que lo que sutilmente se evidencia es que en la complicidad con Tomasa las autoridades del asentamiento se jugaban un interés más alto que tenía que ver con evitar mayores confrontaciones. Las disposiciones de las autoridades monárquicas y locales, como veremos más adelante, recomendaron constantemente mantener la armonía en los puestos fronterizos y entre los efectivos para evitar poner en juego la estabilidad del fuerte.

\section{Latrocinio de mujeres}

Otra práctica que evidencia la pluralidad de cónyuges de las mujeres en la frontera tiene que ver con el "robo" de mujeres o latrocinio fuera de un contexto de cautiverio. ${ }^{42}$ Tres casos contrastan tanto por la violencia, completamente ausente en dos

39. Una denuncia reiterada de los blandengues de la frontera era la falta de aprovisionamiento y el retraso en el pago de los sueldos.

40. Diccionario de Autoridades (Madrid: Real Academia Española, 2013).Junto con la fama, el escándalo era una de las formas de regulación social no estatal ejercida a nivel comunitario.

41. Es importante insistir en que, a diferencia de las causas que se abrieron en los tribunales civiles de la justicia ordinaria, estos casos pertenecían al fuero militar y, en este sentido, las lógicas de la sociabilidad escapaban a las lógicas barriales urbanas que se han estudiado en otros espacios geográficos. Véase María Alejandra Fernández, "Género, sociabilidades y tensiones barriales: el riesgo del desalojo. Buenos Aires, 1780-1820”, Historia y Justicia 11 (2018): 270.

42. El rapto o latrocinio era el robo de una mujer con el fin de corromperla o de casarse con ella; podía ser por fuerza o por seducción. Asunción Lavrin, "La sexualidad en el México colonial: un dilema para la Iglesia", Sexualidad y matrimonio en la América hispánica, siglos XVI-XVIII, coord. Asunción Lavrin (México: Conaculta / Editorial Grijalbo, 1991) 59. 
de ellos y central en el otro, como por la relevancia que la "mala fama" cobra en el segundo. Cuando Mayo y Latrubesse atisban que las mujeres en la frontera no carecían de determinación en la elección de sus itinerantes parejas, apuntan hacia una agencia de las mujeres inusual para el contexto colonial, aunque tampoco se puede omitir el rol, también inusual, que los varones podían jugar en estas prácticas.

En una causa formada en la guardia de Ranchos, en 1787, contra el blandengue Mariano Rojas y su hermano Marcelo por haber herido a Martín de Génova, se reveló una trama de robo de mujer que resultó ser una especie de pacto entre ella, su marido y el acusado. Génova, vecino del matrimonio conformado por Martina González y el blandengue Manuel González alertó a las autoridades por considerar que Marcelo Rojas, de 17 años y de oficio labrador, se estaba robando a Martina, de 24 años. Ambos fueron presentados en el fuerte. Mientras tanto, el blandengue y hermano de Marcelo, llamado Mariano, se trasladó a la casa del denunciante y, acusándolo de "soplón", lo hirió levemente con un cuchillo, por lo que también fue aprehendido. Una vez iniciado el proceso, Martina declaró que no estaba siendo robada, "pues yo tengo el permiso de mi marido para cuando yo quiera hir a las chacras con el expresado Marcelo Rojas a comer o comprar fruta" y aseguró que Mariano hirió a Génova en defensa propia. ${ }^{43}$ Todo pareció aclararse cuando el marido de Martina declaró ante las autoridades que tenía "mucha satisfacción de su mujer", pues él le había recomendado que hallándose "de partida no se fuese con otro a las chacras sino con Marcelo Rojas de quien tiene satisfacción". ${ }^{4}$

De este caso, además de la afabilidad del marido sobre la relación de su esposa con el joven Marcelo, destaca el involucramiento de distintos sectores sociales y una vez más la intención de las autoridades militares de no escalar el conflicto. La acusación fue hecha por Génova, un poblador de origen asturiano que, además de delatar este comportamiento, dio de palos al blandengue Mariano Rojas, hermano mayor de Marcelo. Por otro lado, el blandengue arguyó en su defensa la responsabilidad que tenía de socorrer a su madre, "que es una pobre viuda sin tener otro que la mantenga". Pero, más que mostrarse como una mujer desamparada, durante el proceso se le encontró abogando ante el comandante para pedir la libertad de su hijo. Finalmente, la sentencia ordenó liberar al blandengue y a su hermano, aunque se aconsejaba su traslado a otra compañía. Además, desde Buenos Aires se requirió con énfasis que "se reconcilie a uno y otro con el poblador Luís de Génoba", pero, sobre todo, se exhortaba al comandante a "dedicar su particular atención a que se conserve la paz y la buena armonía entre las tropas y vecinos y pobladores de aquella frontera y que no se haga a estos, ningún mal tratamiento ni se les cause perjuicios ni daños". ${ }^{45}$ Evitar las rencillas entre vecinos y blandengues parece haber ocupado buena parte de las preocupaciones de las autoridades.

43. Manuel de Lizarazu, "Información sumaria sobre Luis de Genoba", Guardia de la Laguna de los Ranchos, 13 de febrero, 1787.AGNA, Buenos Aires, Sala IX, Sumarios Militares, leg. 12-7-6, exp. 9.

44. "Testimonio del Blandengue Manuel González", Guardia de la Laguna de los Ranchos, 4 de marzo de 1787. AGNA, Buenos Aires, Sala IX, Sumarios Militares, leg. 12-7-6, exp. 9.

45. "Carta de Francisco Fernández dirigida al Excelentísimo virrey", Buenos Aires, 2 de mayo 
Un segundo caso fue el "robo de mujer" perpetrado por Dionisio Jaime, desertor reincidente de la sexta compañía de Blandengues, preso en el mismo Fuerte de Ranchos en 1788. A diferencia del caso anterior, este fue violento, lo que se sumó a la "mala fama" de la acusación de deserción como agravante. En su primera defección de la guardia de Luján, cinco años antes, Dionisio había robado dos pistolas, un sable, un biricú y una canana (cinturones), además de cartuchos que pertenecían al sargento Agustín Peralto. ${ }^{46}$ En la segunda deserción, el noveno testigo del caso, el miliciano y labrador Bartolo Domínguez, declaró que el acusado andaba, junto con otro desertor, "de cuadrillero robando caballos y mujeres". ${ }^{47} \mathrm{El}$ mismo Bartolo había sido víctima del "robo" de su mujer, a quien encontró con él en dos ocasiones. En la segunda, intentó quitársela, pero "lo atropelló el dicho Jayme dándole un balazo en el brazo derecho de lo que estuvo bastante tiempo enfermo". Bartolo aseguró que su mujer había sido forzada en ambas ocasiones, "atemorizándola con armas" y que lo creía "por la mala fama que dicho Jayme tenía en el paso de la Magadalena”. ${ }^{48}$ El otro testigo que fue citado para declarar sobre este asunto, Juan Francisco Ramírez, ratificó que el acusado se había llevado por la fuerza a la mujer de Bartolo y fundamentó su creencia en "la fama de guapo" que tenía el acusado. En su confesión, Jaime dijo "que la llevaba al pueblo por su dirección de ella” y que había disparado al marido en defensa propia. Fue sentenciado a seis carreras de baquetas y diez años de presidio.

En este proceso no aparece el testimonio de ella, solo la presunción de su inocencia fundada en la mala fama del blandengue desertor. De acuerdo con Silvia Mallo, "el chisme, la calumnia o la difamación, cumplen con la función de establecer el orden social o de conservarlo". ${ }^{49}$ La "fama de guapo" enunciada por el testigo abonó como agravante a las acciones del acusado. ${ }^{50}$ Además, la fama es construida por el entorno, la comunidad, los vecinos, la familia y los conocidos, quienes vigilan, juzgan y transmiten las opiniones sobre determinada persona; por ello, guarda estricta relación con el honor. Asimismo, la opinión colectiva sobre una persona contribuía a establecer o a negociar los códigos de lo que se consideraba honorable, correcto, y toda aquella práctica que escapara al modelo de lo aceptable podía producir descrédito, deshonra y mala fama. El honor y la honra

de1787. AGNA, Buenos Aires, Sala IX, Sumarios Militares, leg. 12-7-6, exp. 9.

46. "Sumario contra Dionisio Jaime, soldado Blandengue de la $6{ }^{a}$ Compañía”, Fuerte de la Laguna de Ranchos, 1788. AGNA, Buenos Aires, Sala IX, Sumarios Militares, leg. 12-7-3, exp. 5. El detalle de las piezas robadas es idéntico en las declaraciones de varios de los testigos. Según la confesión del acusado solo se llevó dos pistolas.

47. "Testimonio de Bartolo Domínguez”, Fuerte de la Laguna del Monte, 2 de marzo de 1788. AGNA, Buenos Aires, Sala IX, Sumarios Militares, leg. 12-7-3, exp. 5, f. $14 \mathrm{v}$.

48. "Testimonio de Bartolo Domínguez", f. 14v.

49. Silvia Mallo, "Hombres, mujeres y honor. Injurias, calumnias y difamación en Buenos Aires (1770-1840). Un aspecto de la mentalidad vigente”, Estudios de Historia Colonial 13 (1993): 9-27.

50. La fama "se toma por la opinión de alguna persona, buena o mala, conforme a su modo de obrar”. Diccionario de Autoridades (Madrid: Real Academia Española, 2013). 
operaban de manera radicalmente distinta para varones y para mujeres; ${ }^{51}$ no obstante, los códigos ideales que guiaban a la sociedad podían defenderse a través del chismorreo y el rumor e incidir en los juicios civiles o militares como argumento determinante a la hora de establecer la sentencia. ${ }^{52}$ Dionisio era, pues, un individuo con "mala fama" desde su estatus de reincidente. Como lo observó Felipe Tessa en su estudio sobre Chile del siglo XVIII, la mala fama implicaba que "sin importar qué delito cometiesen o del que fueran acusados, cualquier presunta conducta desviada anterior hará que las acusaciones sean tomadas por ciertas", o al menos inclinarán la opinión de los jueces. ${ }^{53}$

Otro "robo de mujer" fue el que cometió José Almada en 1787, cuando desertó de la guardia de Salto y "se llevó" a una mujer casada con la que lo encontraron viviendo en Buenos Aires en un cuarto de la casa de Basilio Almada. ${ }^{54}$ Se dispuso que él fuera arrestado y ella depositada "en la casa que sea de agrado de usted [del sargento mayor de la plaza]" y que se le requisara cualquier bien o alhaja. Sin embargo, durante la aprehensión, el blandengue logró escapar, mientras que ella, encontrada en la cama del susodicho, fue llevada a la Real cárcel. Su nombre era Martina Ruiz y estaba casada con otro blandengue de nombre Antonio Acosta, por cuyos malos tratos había huido. Según su testimonio, el capellán de Salto sabía todo esto e incluso en una ocasión que su marido la había echado de la casa, este procuró y verificó que volvieran a juntarse.

Sobre este caso se quiere hacer énfasis, por un lado, en las redes familiares que permitieron a la pareja amancebada alojarse en la casa del medio hermano del blandengue desertor, lo que convirtió a Basilio Almada en cómplice de la defección y también en encubridor de la relación ilícita. ${ }^{55} \mathrm{La}$ red familiar del desertor incluía a su madre, Andrea Aguilera, quien le había proporcionado 40 ovejas para que las vendiera; el resto de las ovejas las había comprado a otra mujer llamada Rosa Giles. Ambas vivían en los pagos de Arrecifes. Por el otro lado, Martina pertenecía a una familia "de frontera", asentada desde hacía mucho en la guardia de Salto, pues su padre había sido baqueano mientras su "madre, hermanos, hermanas y parientes" seguían ahí, sin saber nada de la amistad con Almada.

51. "La reputación de los hombres aparece asociada a las nociones de 'honor', al 'buen nombre', al 'crédito', a la 'pública fama' y a la 'hombría"'. María Alejandra Fernández, "Reputaciones masculinas y definiciones socioculturales de la hombría. Buenos Aires, 1750-1810", Temas Americanistas 37 (2016): 107.

52. Sobre la fama y el rumor, véase René Salinas Meza, "Fama pública, rumor y sociabilidad", Lo público y lo privado en la historia americana (Santiago de Chile: Fundación Mario Góngora, 2000) 133-154;Verónica Undurraga Schüler, Los rostros del honor. Normas culturales y estrategias de promoción social en Chile colonial, siglo XVIII (Santiago de Chile: Dibam, 2012).

53. Felipe Tessa Bassa,"Desviaciones, control social y administración de justicia en el Reino de Chile durante el s. XVIII”, Intus-Legere Historia 11.2 (2017): 82

54. "Sumaria contra José Almada, acusado del delito de deserción con circunstancia agravante", Guardia de Salto, 15 de marzo a 30 de abril de 1787. AGNA, Buenos Aires, Sala IX, Sumarios Militares, leg. 12-6-7, exp. 10

55. Las ordenanzas también contemplaban severos castigos para los cómplices. Salas 100. 
Resulta relevante distinguir que la causa se abrió oficialmente como "deserción con circunstancia agravante" por haber "robado en aquel dominio a una mujer"; pero en las declaraciones de Martina, transcritas en el juicio, ella reconoce el carácter indebido de su relación, al denominarla "amistad ilícita". La mediación del testimonio oral de ella por el escribano explica parcialmente la introducción de esa categoría en la que cabían lo mismo uniones esporádicas y otras no consagradas por medio del matrimonio, pero estables y perdurables. Martina y José habían sostenido su relación por cinco meses, el mismo tiempo desde que él desertó, pero no habían llegado juntos a la ciudad. Martina llegó sola, de modo que propiamente no la había "robado".

José Almada, como Dionisio en el caso anterior, también era reincidente y acumulaba otros delitos como el robo de armas, por lo que su sentencia fue la misma: seis carreras de baquetas y diez años de presidio. Martina, en cambio, fue calificada por el paisano y peón Valeriano Lezcano como mujer "en buena reputación y crianza de sus dichos padres", ${ }^{56}$ pero su destino fue regresar con su marido, quien declaró ante las autoridades del fuerte de Luján estar dispuesto a ello, pues consideraba que el castigo que ya había tenido Martina "le servirá de escarmiento para que en lo subsiguiente puedan vivir con toda paz y sosiego". 57

\section{5. "Forzar al torpe fin": la urdimbre de un violador en la frontera}

La trama urdida por la denuncia contra Juan Baptista Regueyra es la de mayor escándalo entre los casos revisados, pues se trata de un violador que había cometido al menos siete agresiones contra mujeres. El blandengue, acusado de "insulto", tenía 31 años, pelo castaño y "buen color"; había sentado plaza en el fuerte de Salto desde hacía once años, fue reenganchado en una ocasión y desertó entre 1785 y 1788, llevándose dos pistolas.

Margarita Palomeque, quien denunció el agravio, estaba casada con un miliciano y vecino llamado José Bustos. Frente al comandante de frontera, Nicolás Quintana, Margarita declaró que, mientras estaba en su casa, Regueyra entró a preguntar por su "pariente" (el marido), al mismo tiempo que cerraba la puerta y le decía “vamos jodiendo a esta desvergüenza". Ella intentó escapar, pero él le puso "la rodilla sobre el brazo izquierdo le agarró con las dos manos el otro brazo torciéndoselo y atormentándola contra su mismo catre", 58 a las súplicas respondieron "muchos golpes y puñadas" en la cara; su brazo quedó despellejado, su cara marcada y su espalda hinchada. Cuando Regueyra salía de la casa, se encontró con el marido y lo invitó a comer, con la amenaza de decirle "las cosas que su mujer habla

56. "Declaración del paisano peón Valeriano Lezcano", Guardia de Salto, 27 de marzo de 1787. AGNA, Buenos Aires, Sala IX, Sumarios Militares, leg. 12-6-7, exp. 10.

57. "Presentación del Blandengue José Antonio Acosta ante Francisco Balcarce" Luján, 26 de julio de 1787. AGNA, Buenos Aires, Sala IX, Sumarios Militares, leg. 12-6-7, exp. 10.

58. "Declaración de la herida en la Sumaria contra Juan Bautista Regueyra", Salto, 24 de noviembre de 1790. AGNA, Buenos Aires, Sala IX, Sumarios Militares, leg. 12-7-6, exp. 13. 
de usted”. Margarita se encaminó a casa de su vecina Catalina Giménez a donde volvió a llegar Regueyra en busca de su sombrero, por lo que no pudo decirle nada de lo sucedido. Tampoco su marido reparó en lo desfigurado de su rostro porque llevaba una manta. Fue hasta que Margarita llegó a la casa de su hija, casada con el blandengue Jacinto, que esta dio parte al sargento de la compañía.

Los testigos del juicio dieron cuenta de los casos conocidos de otras mujeres "forzadas" por Regueyra. Dos años antes, un par de hombres habían intentado forzar a Luisa Arce, quien declaró y dijo que durante el asalto reconoció a uno de ellos por su acento andaluz y que el otro la cortó con un cuchillo, pero ambos huyeron cuando su hija disparó un arma para amedrentarlos. Solo reconoció a Regueyra cuando la tía de este llegó a pedirle que no lo denunciara. Después de este ataque, el blandengue desertó de la compañía. A Manuela Naranjo la socorrió una vecina, quien llegó a la calle de donde había logrado salir corriendo Manuela y, con un palo en la mano, amenazó a Regueyra, que entonces las dejó en paz. Cuatro meses antes, Regueyra esperaba, escondido en una zanja, a Gregoria Maciel, quien había salido a atar a una vaca lechera. Cuando comenzó a "forcejear con ella para hecharla en el suelo y conseguir su depravado intento", los "gritos que daba llorando" para llamar a su hermano la salvaron. Asimismo, una noche en la que Manuela Chaparro regresaba de un velorio, logró quitarse a Regueyra de encima porque traía una navaja con la que lo ahuyentó. En otra ocasión, María Juana Farías, viuda de un sargento blandengue, presenció cuando Regueyra arrastraba a Catalina Escobar hacia unas matas; las voces de la viuda asustaron al caballo y con ello él salió huyendo mientras amenazaba a Catalina: "ya con esta ban tres bezes que has querido hazer conmigo esa malda". El capellán de la compañía, Pedro Chaves, tuvo conocimiento de ese caso y de otro cuya queja presentó ante el comandante. Supo queVictoria Garay escapó de las garras de Regueyra "teniendo que ponerse en la calle medio desnuda”. El capellán dijo que en aquella ocasión amonestó al susodicho, pero "silenciosamente porque así convenía al bien estar del matrimonio de la delatante". 59

En su testimonio, el agresor justificó haber golpeado a Margarita "porque era su amiga, esto es, que vivía la mala vida con ella”. Además, la acusó de haberle pedido "en dos mil ocasiones, que viera de darle alguna bebida a su marido para azonzarlo". De Catalina dijo lo mismo: "que era su amiga para fines torpes" y que por su culpa estuvo mucho tiempo preso. Declaró no recordar a ninguna otra mujer. Aun cuando su "pésima e incorregible conducta", su constante embriaguez y el "mal crédito en el particular de querer forzar mujeres" era "bos bulgar en esta frontera", Regueyra intentó descargar su culpa mediante el desprestigio moral de las mujeres a las que había violentado.

Al final de las pesquisas, la sentencia se fijó en diez años de presidio, la misma que para un desertor reincidente. Por un lado, la causa se abrió por "insulto", y el resto

59. "Recado del capellán Pedro Chaves a Nicolás de la Quintana", Guardia de Salto, 25 de noviembre de 1790. AGNA, Buenos Aires, Sala IX, Sumarios Militares, leg. 12-7-6, exp. 13, s.f. 
de los testimonios se asentaron como intentos de violación. Por otro, la definición de esta falta había sido objeto de diversos debates en el derecho canónico, la ley civil española, el Concilio de Trento y las concepciones locales, ${ }^{60}$ pero los castigos no solían ser graves. En muchos casos las mismas víctimas perdonaban al agresor y en otros se pagaba una fianza; en los menos, las penas podían ser de destierro o trabajos.

La negligencia en la persecución y el castigo de los abusos sexuales contra mujeres no era exclusiva de las autoridades de la frontera, pero en este juicio es posible recuperar algunas de las concepciones que guiaron la acusación. En los interrogatorios a las mujeres testigos aparecen fórmulas y eufemismos usados por las autoridades militares para denominar a la violación tales como "forzar", "acometer", "solicitar", "el torpe fin" o "haber estropeado". También se les pregunta si ellas habían tenido algún "trato ilícito o familiar" que pudiera haberle dado lugar a Regueyra para cometer la osadía. A todas les preguntan si habían dado parte de lo sucedido y, de no haberlo hecho, las razones que tuvieron. Gregoria, por ejemplo, no dio parte de oficio, pero sí lo contó en el rancho, por lo que mucha gente lo supo. Manuela Naranjo no lo hizo "para que no le sucediera mal", mientras que Luisa Arce recibió presión de la tía de Regueyra y de la madre del otro agresor para que no los acusara. La mujer de Regueyra "pretendió taparles la boca" y le ofreció a Margarita y a su marido un pañuelo y una camisa en reemplazo de lo que destrozó el acusado.

El inventario de agresiones permite esbozar un panorama de las mujeres de esta frontera. De las siete mujeres agredidas, todas eran casadas, salvo Luisa, quien era viuda. Al socorro de las mujeres violentadas llegaron hijas, vecinas y otras mujeres que pasaban cerca. De igual forma, fue una mujer, la hija de Margarita, quien acusó a Regueyra ante las autoridades, y la hija de Luisa disparó un arma para ayudar a su madre. De ninguna se sabe su edad. En las acciones de todas se despliega la posibilidad de pensar en la existencia de lazos femeninos familiares y de vecindad. Sin embargo, la solidaridad y el apoyo múltiple constituyeron solo una parte de estos vínculos, puesto que otras mujeres encubrieron las agresiones perpetradas por sus familiares.

\section{Consideraciones finales}

Sacar de entre las áridas grietas de la documentación militar rastros de los lazos afectivos, de las expresiones de apoyo mutuo y, en general, de la vida de las mujeres en los diversos fuertes de la frontera bonaerense a finales del siglo XVIII implica una relectura expresamente orientada a encontrar mujeres en un ámbito tradicionalmente concebido como masculino. Este análisis parte de que la deserción opera como un lente a través del cual es posible perfilar formas de sociabilidad y dinámicas cotidianas de la vida en la frontera que tienen en el centro a la transgresión.

60. Joannes Gerson definió el estupro como "el corrompimiento de personas viudas o vírgenes". A esta definición Zumárraga añadió la deshonra y ambos coincidieron en que la violación era un "rapto que es hacerlo ya dicho por fuerza y violentamente". Carmen Castañeda, Violación, estupro y sexualidad. Nueva Galicia 1790-1821 (Guadalajara: Editorial Hexágono, 1989) 64. 
A diferencia de los casos resguardados en fondos documentales producidos por la justicia ordinaria, las causas aquí analizadas no fueron abiertas a mujeres y los delitos perseguidos están subsumidos en el de la deserción de los militares. Es decir, no hay intervención de funcionarios civiles, las informaciones sobre las mujeres son en su mayoría marginales a la causa perseguida y los oficiales encargados de impartir justicia sopesaron durante los procesos aspectos directamente relacionados con el objetivo de defender la frontera. ${ }^{61}$

Las mujeres que aparecen en esta serie de juicios sumarios están, en su mayoría, asociadas a sus roles de madres, hijas y "mujeres de". No obstante, muchas de ellas lograron construir ámbitos de acción diversos que exceden el de la indefensión y trascienden su calidad de víctimas de una violencia masculina profundamente arraigada en la sociedad colonial y exacerbada en "la frontera". De esta forma, fue posible detectar cómo las víctimas reaccionaron y construyeron alternativas para su defensa ante las agresiones, que no solo fueron sexuales, ya que incluían delitos como el robo con violencia, como en el caso deVitorina Arroyo, quien fue asaltada por un blandengue que le robó varias piezas de ropa en el Fuerte de Ranchos en 1786, cuando se dirigía a lavar. ${ }^{62}$ También se encontró que madres, tías y esposas encubridoras de sus hijos desertores o violadores negociaban con otras mujeres e incluso con los comandantes de la frontera.

A partir de una noción de la frontera como espacio de transición, es posible seguir trabajando con la idea de que los modelos y marcos normativos que operaban con mayor eficiencia en los espacios plenamente integrados al orden colonial adquirían mayor maleabilidad en las zonas fronterizas. Si bien el poblamiento del cordón de fuertes y fortines, como parte central de la política defensiva, debía responder a los modelos morales y de civilidad vigentes, sus habitantes enfrentaban dificiles condiciones de subsistencia. La gran movilidad de los varones, la precariedad material y la amenaza constante de ataques complicaban el seguir la ortodoxia de las normas. Esta aparente contradicción se alcanza a ver, por ejemplo, en el empeño de los capellanes y de los militares en preservar los matrimonios sobre cualquier otra consideración, lo que reforzaba la centralidad la familia, aunque al mismo tiempo tuvieran que fungir como cómplices para que los maridos no se enteraran del adulterio de sus mujeres.

En cuanto a la ocupación de las mujeres en la frontera, se encontró la reiteración de "trabajos pertenecientes ha una mujer que bibe en esta guardia", ${ }^{63}$ como hilar y coser, por ejemplo, aunque también había otras que estaban insertas en dinámicas comerciales, como las dos mujeres que comerciaban ovejas, e incluso se encontró noticia de una "mujer médica”, natural de Córdoba, que curó al blandengue Miguel

61. Sobre el fuero militar en el siglo XVIII, véase Emilio Fabián Harari, "La aplicación del fuero militar a la población miliciana en el Río de la Plata", Revista de Estudios Histórico-Jurídicos 35 (2013): 461-479.

62. "Sumario formado contra el soldado José Francisco Roldán por ladrón y desertor", 31 de mayo de 1786. AGNA, Buenos Aires, Sala IX, Sumarios Militares, leg. 12-7-6, exp. 10.

63. "Declaración de Thomasa Cabrera", f. 9v. 
Salas en 1800, durante su segunda deserción. ${ }^{64}$ Con todo, la mayor proporción de los casos revisados alude a aspectos vinculados con la sexualidad de estas mujeres.Y a pesar de haber constatado casos de mujeres que ejercieron prácticas sexoafectivas con diversas parejas, a veces con la venia del marido o con la complicidad de buena parte de la comunidad, en general, la violencia constante, tanto física como verbal, primaba en las relaciones de las mujeres con los varones. Los diversos eufemismos usados para denominar las agresiones sexuales, la búsqueda incesante de atenuantes de la culpabilidad del agresor y los leves castigos dispuestos sugieren un buen grado de indiferencia hacia estas transgresiones. Queda pendiente aún el cotejo de estos niveles de transigencia con los de los centros urbanos en la misma época. Por lo pronto, es posible plantear que el interés por mantener la concordia en los puestos fronterizos, entre los efectivos de los cuerpos de veteranos, los milicianos y los vecinos, resultaba de vital importancia para la seguridad de la frontera, incluso si esto implicaba desestimar algunos delitos y pecados que en contextos urbanos habían sido en sí mismos causas judiciales. En todo caso, centrar la mirada en las mujeres que vivieron en estos fuertes intenta no solo reiterar la obviedad de su existencia en estos espacios, sino rescatar su agencia y con ello comenzar a subvertir, poco a poco, la imagen de la frontera como un espacio predominantemente masculino.

\section{Fuentes}

\section{Manuscritas}

Archivo General de la Nación, Buenos Aires (AGNA)

Sala IX

\section{Impresas}

Diccionario de autoridades. Madrid: Real Academia Española, 2013.

Salas López, Fernando de. Ordenanzas militares en España e Hispanoamérica. Madrid: Editorial Mapfre, 1992.

\section{Bibliografía}

Alemano, María Eugenia. "Los Blandengues de la Frontera de Buenos Aires y los dilemas de la defensa del Imperio (1752-1806)". Fronteras de la Historia 22.2 (2017): 44-74. Doi: 10.22380/20274688.104.

Ambroggio, Eugenia Soledad. "Género y violencia en la Córdoba tardo colonial. La lealtad y el honor en las relaciones formales e informales". XI Jornadas Interescuelas Departamentos de Historia, Universidad de Tucumán, 2007.

64. "Sumario formado contra Miguel Salas soldado de la $3^{a}$ Compañía de Blandengues por desertor reincidente", Frontera de Salto, 12 de noviembre de 1800. AGNA, Buenos Aires, Sala IX, Sumarios Militares, leg. 12-7-7, exp. 12. 
Banzato, Guillermo y Sol Lanteri. "Forjando la frontera. Políticas públicas y estrategias privadas en el Río de la Plata, 1780-1860”. Historia Agraria 43 (2007): 435-458.

Barral, María E. y Raúl O. Fradkin. "Los pueblos y la construcción de las estructuras de poder institucional en la campaña bonaerense (1785-1836)". Boletín del Instituto de Historia Argentina y Americana "Dr. Emilio Ravignani" 27 (2005): 7-48.

Bridikhina, Eugenia. Sin temor a Dios ni a la justicia real. Control social en Charcas a fines del siglo XVIII. La Paz: Instituto de Estudios Bolivianos / Universidad Mayor de San Andrés, 2000.

Canedo, Mariana. "Fortines y pueblos en Buenos Aires del siglo XVIII. ¿Una política de urbanización para la frontera?”. Mundo Agrario 7.13 (2006).

Carlón, Florencia. "Sobre la articulación defensiva en la frontera sur bonaerense a mediados del siglo XVIII: un análisis a partir de la conflictividad interétnica". Anuario del Centro de Estudios Históricos "Prof. Carlos S. A. Segreti" 8.8 (2008): 277-298.

Castañeda, Carmen. Violación, estupro y sexualidad. Nueva Galicia 1790-1821. Guadalajara: Editorial Hexágono, 1989.

Clavero, Bartolomé. “Delito y pecado. Noción y escala de transgresiones”. Sexo barroco y otras transgresiones premodernas. Comps. Francisco Tomás y Valiente y otros. Madrid: Alianza Editorial, 1990.

Contente, Claudia. "Las mujeres, sus bienes y estado civil, entre costumbres y legislación. Las jefas de familia de la campaña de Buenos Aires de los siglos XVIII y XIX”. Revista de Historiografía 26 (2017): 67-83. Doi: 10.20318/ revhisto.2017.3699.

Fernández, María Alejandra. "Familias en conflicto: entre el honor y la deshonra". Boletín del Instituto de Historia Argentina y Americana "Dr. Emilio Ravignani” 20 (1999): 7-43.

. "Género, sociabilidades y tensiones barriales: el riesgo del desalojo. Buenos Aires, 1780-1820". Historia y Justicia 11 (2018): 262-289.

. "Reputaciones masculinas y definiciones socioculturales de la hombría. Buenos Aires, 1750-1810”. Temas Americanistas 37 (2016): 105-128.

Fradkin, Raúl O. “Las milicias de caballería de Buenos Aires, 1752-1805”. Fronteras de la Historia 19.1 (2014): 124-150.

Fraschina, Alicia. Mujeres consagradas en el Buenos Aires colonial. Buenos Aires: Eudeba, 2010.

Fuentes-Barragán, Antonio. "Quebrantos de la moral conyugal: amistades ilícitas en el Buenos Aires tardocolonial".Naveg@mérica 15 (2015):1-23.

González, Yéssica. "Indias blancas tierra adentro. El cautiverio femenino en la Frontera de la Araucanía, siglos XVIII y XIX”. Anuario Colombiano de Historia Social y de la Cultura 43.2 (2016): 185-214. Doi: 10.15446/achsc. v43n2.59076. 
Gutiérrez Aguilera, María Selina. "Conductas violentas, realidades cotidianas. Familia, sociedad y convivencia en el Buenos Aires del siglo XVIII". Procesos Históricos. Revista de Historia y Ciencias Sociales 28 (2015) 76-91.

. "Mujeres agregadas en el Buenos Aires del siglo XVIII: caridad y solidaridad”. Nuevo Mundo Mundos Nuevos. Débats (2012). Doi: 10.4000/ nuevomundo.64111.

. "Mujeres esclavas bajo la autoridad femenina: entre dóciles y rebeldes. (Buenos Aires, siglo XVIII)". Historia y Memoria 12 (2016): 121-155.

. "Mujeres trabajadoras: la subsistencia en el Buenos Aires del siglo XVIII". El Futuro del Pasado 3 (2012): 67-90.

Harari, Emilio Fabián. "La aplicación del fuero militar a la población miliciana en el Río de la Plata". Revista de Estudios Histórico-Jurídicos 35 (2013): 461-479.

Kluger, Viviana. "El expediente judicial como fuente para la investigación histórico-jurídica. Su utilidad para el estudio de la historia de la familia colonial iberoamericana". Passagens. Revista Internacional de História Política e Cultura Jurídica 1.1 (2009): 1-14. Doi: 10.5533/1984-2503-20091104.

Lamas, Alejandra y Guillermo O. Quinteros. "Violencia intrafamiliar y acción judicial en Buenos Aires, 1785-1821". Familias de ayer y de hoy: las sociedades ibéricas y el Río de la Plata. Comps. Guillermo O. Quinteros y M. Pablo Cowen. La Plata: Universidad Nacional de La Plata, 2018.

Lavrin, Asunción. "La sexualidad en el México colonial: un dilema para la Iglesia". Sexualidad y matrimonio en la América hispánica, siglos XVI-XVIII. Coord. Asunción Lavrin. México: Conaculta / Editorial Grijalbo, 1991.

Lozano Armendares, Teresa. No codiciarás la mujer ajena. El adulterio en las comunidades domésticas novohispanas. Ciudad de México, siglo XVIII. México: Universidad Nacional Autónoma de México, 2005.

Mallo, Silvia. "Hombres, mujeres y honor. Injurias, calumnias y difamación en Buenos Aires (1770-1840). Un aspecto de la mentalidad vigente”. Estudios de Historia Colonial 13 (1993): 9-27.

."La mujer rioplatense a fines del siglo XVIII. Ideales y realidad". Anuario del IEHS 5 (1990): 117-132.

Mateo, José. Población, parentesco y red social en la frontera. Lobos (provincia de Buenos Aires) en el siglo XIX. Mar del Plata: Grupo de Investigación en Historia Rural Rioplatense, Universidad Nacional de Mar del Plata, 2001.

Mayo, Carlos A. "Amistades ilícitas: las relaciones extramatrimoniales en la campaña bonaerense, 1750-1810”. Cuadernos de Historia Regional 2 (1985): 3-9.

. Estancia y sociedad en La Pampa (1740-1820). Buenos Aires: Biblos, 1995.

Mayo, Carlos A. y Amalia Latrubesse. Terratenientes, soldados y cautivos: la frontera, 1736-1815. Mar del Plata: Universidad Nacional de Mar del Plata / Colegio Nacional Dr. Arturo U. Illia / Grupo Sociedad y Estado, 1993.

Moreno, José Luis. "Conflicto y violencia familiar en el Río de la Plata 17701810". Revista de Historia Social y de las Mentalidades 6 (2002): 13-38. 
Moreno, José Luis y José Antonio Mateo. “El 'redescubrimiento' de la demografia histórica en la historia económica y social". Anuario IEHS 12 (1997):35-55.

Néspolo, Eugenia Alicia. “La 'Frontera' Bonaerense en el siglo XVIII un espacio políticamente concertado: fuertes, vecinos, milicias y autoridades civilesmilitares". Mundo Agrario 7.13 (2006): 1-27.

Olivero, Sandra. "Hogares femeninos en el Buenos Aires colonial". Nuevo Mundo Mundos Nuevos. Colloques (2008). Doi: 10.4000/nuevomundo.43783.

Ortelli, Sara. "La frontera y el mundo indígena pampeano". Historia de la provincia de Buenos Aires. Tomo 2. Dir. Raúl O. Fradkin. Buenos Aires: Edhasa, 2012.

Pérez Gerardo, Diana Roselly. "Blandengues desertores: dinámicas sociales de frontera en Buenos Aires a finales del siglo XVIII". Fronteras de la Historia 25.2 (2020): 94-118. Doi: 10.22380/20274688.1141.

Ratto, Silvia. "El debate sobre la frontera a partir de Turner. La New Western History, los Borderlands y el estudio de la frontera en Latinoamérica”. Boletín del Instituto de Historia Argentina y Americana "Dr. Emilio Ravignani" 24 (2001): 105-141.

Roulet, Florencia. "Fronteras de papel. El periplo semántico de una palabra en la documentación relativa a la frontera sur rioplatense de los siglos XVIII y XIX”. Revista Tefros 4.2 (2006): 1-26.

. "Mujeres, rehenes y secretarios: mediadores indígenas en la frontera sur del Río de la Plata durante el período hispánico”. Colonial Latin American Review 18.3 (2009): 303-337. Doi: 10.1080/10609160903336101.

Salerno, Natalia Soledad. "Mujeres indígenas recluidas en la Casa de Recogimiento (Buenos Aires, etapa colonial tardía)". Tesis de licenciatura en Historia, Universidad Nacional del Sur, 2014.

Salinas Meza, René. "Fama pública, rumor y sociabilidad". Lo público y lo privado en la historia americana. Santiago de Chile: Fundación Mario Góngora, 2000.

Socolow, Susan M. "Buenos Aires: Puerto Atlántico e Hinterland en el siglo XVIII". Revista de Estudios Marítimos y Sociales 2.2 (2009): 9-20.

Tamagnini, Marcela y Graciana Pérez Zavala. "Mujeres de frontera: entre el cautiverio y el estigma". IV Congreso Chileno de Antropología, Colegio de Antropólogos de Chile, 2001.

Tessa Bassa, Felipe. "Desviaciones, control social y administración de justicia en el Reino de Chile durante el s. XVIII”. Intus-Legere Historia 11.2 (2017): 61-85.

Undurraga Schüler,Verónica. Los rostros del honor. Normas culturales y estrategias de promoción social en Chile colonial, siglo XVIII. Santiago de Chile: Dibam, 2012.

Vassallo, Jaqueline. "Delincuentes y pecadoras en la Córdoba tardo colonial". Anuario de Estudios Americanos 63.2 (2006): 97-116.

. “Historia de las mujeres o historia de género? Una aproximación al estudio de las mujeres en la ciudad de Córdoba a fines del siglo XVIII”. Revista Dos Puntas 6.11 (2015): 153-178.

Yanzi Ferreira, Ramón Pedro. "Los delitos de orden sexual: violencia, incesto y estupro en la jurisdicción de Córdoba del Tucumán (siglo XVIII)”. Cuaderno de Historia 15 (2005): 28-45. 